\title{
Prevalence of Depressive Disorders and Associated Factors among Adult Population of Dubai 2019
}

\author{
Mona Abdullatif Sobya Farooq Ayesha Altheeb Fidaa Rishmawi \\ Hana Jaradat Kadhim AlAbady \\ Programs \& Studies, Public Health Protection Department, Dubai Healthcare Corporation, Dubai Health Authority, \\ Dubai, UAE
}

\section{Keywords \\ Mental health - Depressive disorders · Prevalence · \\ Depression · Population survey · Dubai · UAE · Middle East}

\begin{abstract}
Background: Globally, depressive disorders are one of the leading causes of ill mental health and disability affecting about 1 in 4 people at some point in their lives. Populationlevel data on depressive disorders in the region are sparse yet essential for health sectors. This is the first population estimate for the prevalence of depressive disorders and associated factors in Dubai. Objective: The aim of this study was to estimate the prevalence of depressive disorders and the associated factors among adults aged $\geq 18$ years in the Emirate of Dubai 2019. Method: This is a complex-design cross-sectional population survey targeting Dubai residents aged $\geq 18$ years. This study was part of the Dubai Household Survey 2019 (DHHS-2019). The total number of participants was 2,244 , with a response rate of $91.6 \%$. The design was a 2-stage stratified cluster sample. Trained investigators conducted computer-assisted face-to-face interviews using the World Health Survey questionnaire and Patient Health Questionnaire (PHQ-9) screening. Analysis was design-based adjusting for weight, primary sampling unit, and stratum. $\boldsymbol{R} \boldsymbol{e}$ -
\end{abstract}

sults: The overall prevalence of depressive disorders was $2.3 \%$ (95\% confidence interval [Cl]: 1.6\%-3.4\%). Screening revealed $1.9 \%$ (95\% Cl: $1.2 \%-2.9 \%)$ of participants were positive for depressive disorders, with no prior diagnosis constituting approximately $74 \%$ of the depressed. Factors associated with depression were adjusted using logistic regression and revealed significantly higher odds of depressive disorders among the following: unmarried (single, divorced, and widowed) comparing to married (odds ratio [OR]: 2.7, 95\% $\mathrm{Cl}$ : 1.2-6.3) and smokers than nonsmokers (OR: 3.3, 95\% Cl: 1.4-8.0). Employment was found to be a protective factor and reduced the odds of having depressive disorders by $80 \%$ comparing to unemployed (OR: $0.2,95 \% \mathrm{Cl}$ : 0.1-0.7). Moreover, those suffering from health conditions had higher odds for having depressive disorders, such as chest pain (OR: 20.2, 95\% Cl: 5.5-74.8), history of tuberculosis (TB) (OR: 12.6, 95\% $\mathrm{Cl}: 2.1-76.8)$, and history of stroke (OR: $22.5,95 \% \mathrm{Cl}: 6.8-$ 74.2). Conclusion: The prevalence of depressive disorders was relatively low in Dubai compared to most countries. However, approximately $74 \%$ of individuals with depression were undiagnosed, indicating the need for screening programs. The odds of having depressive disorders were significantly higher among unmarried, unemployed, smokers, and those with a history of TB and stroke.

(C) 2021 The Author(s)

Published by S. Karger AG, Basel karger@karger.com www.karger.com/dmj

Karger $\stackrel{\text { ' }}{5}$

BOPEN ACCESS
(C) 2021 The Author(s)

Published by S. Karger AG, Basel

This is an Open Access article licensed under the Creative Commons Attribution-NonCommercial-4.0 International License (CC BY-NC) (http://www.karger.com/Services/OpenAccessLicense), applicable to the online version of the article only. Usage and distribution for commercial purposes requires written permission. 


\section{Introduction}

Mental health disorders are important public health problems linked to diminished role functioning and quality of life, high morbidity, and mortality [1]. Mental health disorders include depression, bipolar affective disorder, schizophrenia, and other psychoses [2].

In 2010, the Global Burden of Disease (GBD) study identified depressive disorders as a leading cause of ill health. Moreover, major depressive disorders were found to be a major contributor to the global burden of suicide and ischemic heart disease. The World Health Organization (WHO) emphasizes the importance of including depressive disorders as a public health priority and implementing cost-effective interventions to reduce the burden [3].

Depressive disorders are characterized by sadness, loss of interest or pleasure, feelings of guilt or low self-worth, disturbed sleep or appetite, feelings of tiredness, and poor concentration. It can be long-lasting or recurrent, substantially impairing an individual's ability to function or cope with daily life. Severe depression can sometimes even lead to suicide [4].

Depressive disorders are the most common mental health disorders affecting an estimated 264 million globally. The WHO has reported the prevalence of depression in population surveys using 3 different tools. The first tool was the Diagnostic Interview Schedule, which was used in 10 countries, and estimated a lifetime prevalence of depression ranging from 1.5\% (Taiwan) to $19.0 \%$ (Beirut), with the midpoints at 9.2\% (West Germany) and 9.6\% (Edmonton, Canada). Twelve-month prevalence estimates ranged from $0.8 \%$ (Taiwan) to $5.8 \%$ (Christchurch, New Zealand), with the midpoints at 3.0\% (the USA), and 4.5\% (Paris) [5]. The second tool was the World Mental Health Survey (WMHS) reporting a 3.2\% 12 -month average prevalence of depression across 60 countries [6]. The third and latest tool was the World Mental Health Survey (WMHS) using Composite International Diagnostic Interview (CIDI) version 3.0. The 12 -month prevalence estimates ranged from $2.2 \%$ (Japan) to $10.4 \%$ (Brazil). The midpoint across all countries was similar to that in previous surveys (5\%), as was the weighted 12-month average prevalence for the 10 highincome (5.5\%) and 8 low- to middle-income countries (5.9\%) [7]. In India, the prevalence of lifetime and current depressive disorders was 5.25 and $2.68 \%$, respectively [8]. In Dubai (1989), a psychiatric community study targeting the national Emirati female population estimated the prevalence of depressive disorders to be $13.7 \%$, at a time when the general population of Dubai was approximately 400,000 persons, and the ratio of nationals to nonnationals was 1:3 [9].

This is the first population survey reporting depressive disorders for both nationals and nonnationals, and males and females among the approximately 3 million inhabitants of cosmopolitan Dubai, where the ratio between national and nonnational reached 1:9. This study is important because it provides baseline information for policy makers in the field of population mental health.

\section{Methodology}

\section{Objective}

The objective of the study was to estimate prevalence of depressive disorders among the adult population aged $>18$ years in the Emirate of Dubai in 2019 along with the associated risk factors.

\section{Survey Design and Setting}

The study was a multistage stratified cross-sectional population survey carried out as part of the Dubai Household Survey 2019 (DHHS-2019) in the Emirate of Dubai, during the period 6 February 2019-30 March 2019. The target population included all adults residing in households in the Emirate of Dubai in 2019. The types of households included UAE national and non-UAE national families, collective households, and labor camps. However, for the purpose of this study, laborers were excluded.

\section{Sample Design}

The design and methodology of DHHS-2019 were based on the 2 international surveys including (a) Living Standards Measurement Surveys (LSMSs) for World Bank and (b) World Health Survey (WHS) from the WHO. The sample was a 2-stage stratified cluster. During the first stage, enumeration areas were selected randomly, and during the second stage, households from each enumeration area were also selected randomly. Cluster size ranged from 100 to 200 households. Kish tables were used for randomly selecting 1 adult aged 18 years or older.

Sample size for DHHS-2019 was calculated based on (a) design effect with a coefficient of 1.5 , (b) prevalence of $18.5 \%$ for diabetes among UAE nationals and $11 \%$ among non-UAE nationals, and (c) a confidence level of $95 \%$ and a margin of error of $17 \%$ from a diabetes prevalence of $18.5(e=3.1)$. Emiratis and females were oversampled and at analysis were corrected with weighting.

Based on the above and with consideration of a $91.6 \%$ response rate, the total sample size summed up to 2,532 adults. Because we assume that the prevalence of depressive disorders is less than the prevalence of diabetes, the calculated sample size will be more than the minimum sample size needed to estimate the prevalence of depressive disorders and the error will be $<3.1 \%$. For the purposes of this study, we excluded laborers to give a total sample of 2,244 adults in our study.

Data were collected using a standardized valid questionnaire adapted from the WHS developed by the WHO with incorporation of the Patient Health Questionnaire (PHQ-9) - depression severity developed by the CDC. Trained investigators conducted 
Table 1. Sociodemographic characteristics of adult population aged $\geq 18$ years in Dubai 2019

\begin{tabular}{|c|c|c|c|c|c|c|}
\hline Sociodemographic characteristic & $n$ & Weighted, \% & & $95 \% \mathrm{Cl}$ & Deft & Total \\
\hline \multicolumn{7}{|l|}{ Age, years } \\
\hline $18-35$ & 933 & 49.2 & 45.7 & 52.6 & 1.7 & \multirow{3}{*}{2,244} \\
\hline $36-59$ & 967 & 45.2 & 42.0 & 48.5 & 1.5 & \\
\hline $60+$ & 344 & 5.6 & 4.5 & 7.0 & 1.2 & \\
\hline \multicolumn{7}{|l|}{ Gender } \\
\hline Female & 1,022 & 38.2 & 35.0 & 41.4 & 1.5 & \multirow{2}{*}{2,244} \\
\hline Male & 1,222 & 61.8 & 58.6 & 65.0 & 1.5 & \\
\hline \multicolumn{7}{|l|}{ Marital status } \\
\hline Married & 1,489 & 71.3 & 68.1 & 74.2 & 1.6 & \multirow{2}{*}{2,244} \\
\hline Not married & 755 & 28.8 & 25.8 & 31.9 & 1.6 & \\
\hline \multicolumn{7}{|l|}{ Educational level } \\
\hline Illiterate & 102 & 1.2 & 0.8 & 1.8 & 1.1 & \multirow{4}{*}{2,244} \\
\hline Some schooling & 382 & 12.7 & 10.5 & 15.4 & 1.8 & \\
\hline High school & 478 & 17.0 & 14.6 & 18.0 & 1.7 & \\
\hline College or higher & 1,282 & 69.0 & 65.0 & 72.8 & 2.0 & \\
\hline \multicolumn{7}{|l|}{ Employment status } \\
\hline Unemployment & 47 & 1.6 & 0.9 & 2.6 & 1.5 & \multirow{3}{*}{2,244} \\
\hline Out of workforce & 704 & 20.2 & 17.6 & 23.1 & 1.6 & \\
\hline Employed & 1,493 & 78.1 & 75.3 & 80.8 & 1.6 & \\
\hline
\end{tabular}

Deft, design factor; $\mathrm{Cl}$, confidence interval.

face-to-face interviews; data were captured electronically and checked for inconsistency on site.

The prevalence of depressive disorders was estimated by adding the proportion of individuals self-reporting a diagnosis of depression to those screened positive using the PHQ-9 [10]. Selfreported depression diagnosis was defined as adult respondents (aged $\geq 18$ years) who reported that they had ever been diagnosed with depression by a doctor. Screening for depressive disorders was conducted using the PHQ-9, a symptom-screening questionnaire, which allows for criteria-based diagnoses of depressive disorders to estimate the proportion of depressive disorders. The definition of screened positive cases was defined, if the respondent met at least 4 criteria from the PHQ-9 lasting over 2 weeks prior to the interview.

\section{Statistical Analysis}

Data analysis was performed using STATA-12. All analyses incorporated survey design factors, including weighting, stratum, and primary sampling unit. Frequencies and weighted percentages were presented to summarize categorical variables, and design factor (Deft) was presented as a measure of relative efficiency for the results estimated from complex sample survey data compared with a sample of equivalent size selected by a simple random sample (SRS) design.

The difference between percentages was examined using Pearson's corrected $\chi^{2}$ test with second-order Rao-Scott correction suitable for both sparse and nonsparse tables and reported as $F$ test [11]. The level of significance was set at $p<0.05$. Logistic regression was used and reported with odds ratio (OR), the model goodness of fit was calculated using the $F$-adjusted mean residual test for complex-design surveys [12].

Depressive Disorders and Associated Factors among Adult Population of Dubai

\section{Results}

Table 1 shows the sociodemographic characteristics of the sample population. Total sample size was 2,244 adults aged $\geq 18$ years. Comparable to the population of Dubai 2018 , the sample was dominated by younger age-groups, with $49 \%$ aged between 18 and 35 years, $45 \%$ between 36 and 59 years, and only $6 \%$ elderly. Moreover, female individuals constituted 38.2 and male individuals $61.8 \%$ of the total sample [13]. Regarding marital status, the sample revealed that about $71 \%$ of participants reported being married, while $26 \%$ single, $2 \%$ divorced, and $1 \%$ widowed.

For the educational level, $69 \%$ had college or higher degrees and only about 1.2\% reported illiteracy. Employment status showed that about $78 \%$ were employed, while $1.6 \%$ were unemployed. Table 2 presents distribution of depressive disorders, noncommunicable disease (NCD) risk factors, and some chronic health conditions.

The overall prevalence of depressive disorders including those who self-reported a diagnosis of depression and those who were screened positive for depressive disorders using the PHQ-9 tool was 2.3\% (95\% confidence interval [CI]: $1.6 \%-3.4 \%)$, of those $74 \%(n=62)$ screened positive from the total depressive disorders $(n=84)$ did not report a previous diagnosis of depression. The survey examined 
Table 2. Prevalence of depressive disorders and other health conditions among adult population aged $\geq 18$ years in Dubai $2019(N=224)$

\begin{tabular}{|c|c|c|c|c|c|}
\hline & $n$ & Weighted, \% & \multicolumn{2}{|c|}{$95 \% \mathrm{Cl}$} & Deft \\
\hline \multicolumn{6}{|l|}{ Depressive disorders } \\
\hline Positive by WHS questionnaire & 22 & 0.4 & 0.2 & 0.8 & 0.9 \\
\hline Positive by screening (PHQ-9) & 62 & 1.9 & 1.2 & 2.9 & 1.4 \\
\hline \multicolumn{6}{|l|}{ Total depressive disorders } \\
\hline Yes & 84 & 2.3 & 1.6 & 3.3 & \multirow{2}{*}{1.3} \\
\hline No & 2,160 & 97.7 & 96.7 & 98.4 & \\
\hline \multicolumn{6}{|l|}{ Risk factors and health conditions } \\
\hline Smoking & 357 & 15.7 & 13.6 & 18.2 & 1.5 \\
\hline \multicolumn{6}{|l|}{ BMI } \\
\hline Normal & 595 & 35.8 & 32.5 & 39.3 & 1.55 \\
\hline Underweight & 34 & 2.2 & 1.3 & 3.7 & 1.7 \\
\hline Overweight & 712 & 42.0 & 38.7 & 45.3 & 1.4 \\
\hline Obese & 512 & 20.0 & 17.7 & 22.5 & 1.3 \\
\hline Moderate physical activity & 542 & 24.9 & 22.0 & 28.0 & 1.6 \\
\hline Chest pain & 73 & 1.8 & 1.2 & 2.8 & 1.3 \\
\hline Hypertension & 657 & 26.4 & 23.6 & 29.3 & 1.5 \\
\hline Diabetes & 498 & 18.6 & 16.0 & 21.5 & 1.7 \\
\hline Asthma & 78 & 2.3 & 1.6 & 3.4 & 1.4 \\
\hline Cancer & 17 & 0.3 & 0.1 & 0.6 & 0.9 \\
\hline Stroke & 14 & 0.1 & 0.0 & 0.1 & 0.4 \\
\hline TB & 92 & 2.9 & 2.0 & 4.1 & 1.5 \\
\hline
\end{tabular}

Deft, design factor; Cl, confidence interval; WHS, World Health Survey; PHQ, Patient Health Questionnaire; BMI, body mass index; TB, tuberculosis.

some NCD risk factors and found that $15.7 \%(95 \% \mathrm{CI}$ : $13.6 \%-18.2 \%)$ were current smokers and $62 \%$ were overweight or obese. Those who performed moderate physical activity were $25 \%$ (95\% CI: 22\%-28\%). Among NCDs, hypertension was $26 \%$ (95\% CI: $24 \%-29 \%)$, diabetes was 19\% (95\% CI: 16\%-22\%), and other NCDs, like stroke, asthma, and cancer accounted for $<3 \%$ of the study population.

Table 3 illustrates the distribution of depressive disorders by sociodemographic and health conditions. For demographic characteristics, a significant relationship was found between depressive disorders and marital status, being unmarried had a significantly higher prevalence of depressive disorder than married (4 vs. 1.6\%, respectively, $p<0.05)$. Among common NCD risk factors, current smoking status was significantly associated with depressive disorders as smokers presented with 5.6 and nonsmokers with $1.7 \%(p<0.05)$.

In terms of health conditions, self-reported respiratory conditions had a significant association with depressive disorders, such that $38 \%$ of those with chest pain had depressive disorder compared with $1.7 \%$ of those without chest pain ( $p$ value $<0.001$ ), $28 \%$ of those with asthma had depressive disorders compared with $1.7 \%$ of those without asthma ( $p$ value $<0.001$ ), and $23 \%$ of those with TB had depressive disorder compared with $1.7 \%$ of those without TB ( $p$ value $<0.001$ ). Further, $34.7 \%$ of those with a history of stroke had depressive disorder compared with $2.3 \%$ of those without a history of stroke with high significance $(p<0.001)$.

Table 4 presents a logistic regression model studying the association between sociodemographic indicators, NCD risk factors, and other health conditions with depressive disorders. Table 4 shows that in terms of sociodemographic factors, being unmarried had 2.7 times higher odds of having depressive disorders than being married. Employed people had 0.2 times lower odds of having depressive disorders than being unemployed. For NCD risk factors, Table 4 demonstrates that smokers had a 3.3 times higher chance of having depressive disorders than nonsmokers.

When examining chronic diseases, those who had a history of chest pain had a 20 times higher chance of being depressed than those who did not have chest pain. Further, those who had a history of TB had 12.6 times higher odds of being depressed than those who had not 
Table 3. Depressive disorders by sociodemographic, NCD risk factors, and chronic health conditions among adult population aged $\geq 18$ years in Dubai 2019

\begin{tabular}{|c|c|c|c|c|c|}
\hline \multirow[t]{2}{*}{ Associated factor } & \multicolumn{2}{|c|}{ Depressive disorders } & \multirow{2}{*}{$\begin{array}{l}\mathrm{X}^{2} \text { with second-order } \\
\text { Rao-Scott correction }\end{array}$} & \multirow[t]{2}{*}{$p$ value } & \multirow[t]{2}{*}{ Deft } \\
\hline & $\begin{array}{l}\text { yes } \\
(n=84)\end{array}$ & $\begin{array}{l}\text { total } \\
(n=2,244)\end{array}$ & & & \\
\hline \multicolumn{6}{|l|}{ Gender } \\
\hline \multicolumn{6}{|l|}{ Female } \\
\hline$N$ & 50 & 1,022 & \multirow{2}{*}{$F(1,179)=0.0285$} & \multirow{2}{*}{0.86} & \multirow{2}{*}{$0.9-1.6$} \\
\hline$\%(95 \% \mathrm{Cl})$ & $2.4(1.6-3.6)$ & 100 & & & \\
\hline \multicolumn{6}{|l|}{ Male } \\
\hline$N$ & 34 & 1,222 & & & \\
\hline$\%(95 \% \mathrm{Cl})$ & $2.3(1.3-4.0)$ & 100 & & & \\
\hline \multicolumn{6}{|l|}{ Age-groups, years } \\
\hline $18-29$ & & & \multirow{3}{*}{$F(3.53,631.24)=0.5125$} & \multirow{3}{*}{0.70} & \multirow{3}{*}{$0.8-1.6$} \\
\hline$N$ & 14 & 470 & & & \\
\hline$\%(95 \% \mathrm{Cl})$ & $2.1(1.1-4.1)$ & 100 & & & \\
\hline \multicolumn{6}{|l|}{$30-39$} \\
\hline$N$ & 29 & 754 & & & \\
\hline$\%(95 \% \mathrm{Cl})$ & $2.6(1.3-5.0)$ & 100 & & & \\
\hline \multicolumn{6}{|l|}{$40-49$} \\
\hline$N$ & 17 & 454 & & & \\
\hline$\%(95 \% \mathrm{Cl})$ & $2.4(1.1-5.2)$ & 100 & & & \\
\hline \multicolumn{6}{|l|}{$50-59$} \\
\hline$N$ & 6 & 222 & & & \\
\hline$\%(95 \% \mathrm{Cl})$ & $0.9391(0.2-3.5)$ & 100 & & & \\
\hline \multicolumn{6}{|l|}{$60+$} \\
\hline$N$ & 18 & 344 & & & \\
\hline$\%(95 \% \mathrm{Cl})$ & $3.2(1.4-7.2)$ & 100 & & & \\
\hline \multicolumn{6}{|l|}{ Education } \\
\hline Illiterate & & & & & \\
\hline$N$ & 7 & 102 & & & \\
\hline$\%(95 \% \mathrm{Cl})$ & $2.4(1.1-5.5)$ & 100 & $r(2.19,391.60)=0.1 / / 2$ & 0.86 & $0.3-1.5$ \\
\hline Some schoolin & & & & & \\
\hline$N$ & 21 & 382 & & & \\
\hline$\%(95 \% \mathrm{Cl})$ & $2.1(0.96-4.7)$ & 100 & & & \\
\hline High school col & & & & & \\
\hline$N$ & 19 & 478 & & & \\
\hline$\%(95 \% \mathrm{Cl})$ & $1.9(0.9-3.9)$ & 100 & & & \\
\hline Diploma or hig & & & & & \\
\hline$N$ & 37 & 1,282 & & & \\
\hline$\%(95 \% \mathrm{Cl})$ & $2.4(1.5-3.9)$ & 100 & & & \\
\hline Marital status & & & & & \\
\hline Married & & & & & \\
\hline$N$ & 36 & 1,489 & & & $12-16$ \\
\hline$\%(95 \% \mathrm{Cl})$ & $1.6(0.9-2.9)$ & 100 & $r(1,1 / 9)=6.0991$ & 0.015 & $1.2-1.6$ \\
\hline Unmarried & & & & & \\
\hline$N$ & 48 & 755 & & & \\
\hline$\%(95 \% \mathrm{Cl})$ & $4.1(2.6-6.5)$ & 100 & & & \\
\hline Employment & & & & & \\
\hline Unemployed & & & & & \\
\hline$N$ & 8 & 47 & & & $086-15$ \\
\hline$\%(95 \% \mathrm{Cl})$ & $9.0(3.5-21.52)$ & 100 & $F(1.94,348.03)=3 . / 668$ & 0.03 & $0.86-1.5$ \\
\hline Out of workforc & & & & & \\
\hline$N$ & 37 & 704 & & & \\
\hline$\%(95 \% \mathrm{Cl})$ & $2.5(1.5-4.1)$ & 100 & & & \\
\hline
\end{tabular}


Table 3 (continued)

\begin{tabular}{|c|c|c|c|c|c|}
\hline \multirow[t]{2}{*}{ Associated factor } & \multicolumn{2}{|c|}{ Depressive disorders } & \multirow{2}{*}{$\begin{array}{l}\mathrm{X}^{2} \text { with second-order } \\
\text { Rao-Scott correction }\end{array}$} & \multirow[t]{2}{*}{$p$ value } & \multirow[t]{2}{*}{ Deft } \\
\hline & $\begin{array}{l}\text { yes } \\
(n=84)\end{array}$ & $\begin{array}{l}\text { total } \\
(n=2,244)\end{array}$ & & & \\
\hline \multicolumn{6}{|l|}{ Employed } \\
\hline$N$ & 39 & 1,493 & & & \\
\hline$\%(95 \% \mathrm{Cl})$ & $2.1(1.3-3.4)$ & 100 & & & \\
\hline \multicolumn{6}{|l|}{ Smoking } \\
\hline \multicolumn{6}{|l|}{ Yes } \\
\hline$N$ & 25 & 357 & \multirow{2}{*}{$F(1,179)=9.8118$} & \multirow{2}{*}{0.002} & \multirow{2}{*}{1.3} \\
\hline$\%(95 \% \mathrm{Cl})$ & $5.6(3.1-10.1)$ & 100 & & & \\
\hline \multicolumn{6}{|l|}{ No } \\
\hline$N$ & 59 & 1,887 & & & \\
\hline$\%(95 \% \mathrm{Cl})$ & $1.7(1.1-2.8)$ & 100 & & & \\
\hline \multicolumn{6}{|l|}{ BMI } \\
\hline \multicolumn{6}{|l|}{ Normal } \\
\hline$N$ & 18 & 595 & \multirow{2}{*}{$F(2.48,441.48)=1.2319$} & \multirow{2}{*}{0.3} & \multirow{2}{*}{$0.7-1.6$} \\
\hline$\%(95 \% \mathrm{Cl})$ & $1.7(0.9-3.3)$ & 100 & & & \\
\hline \multicolumn{6}{|l|}{ Underweight } \\
\hline$N$ & 2 & 34 & & & \\
\hline$\%(95 \% \mathrm{Cl})$ & $1.5(0.2-8.7)$ & 100 & & & \\
\hline \multicolumn{6}{|l|}{ Overweight } \\
\hline$N$ & 27 & 712 & & & \\
\hline$\%(95 \% \mathrm{Cl})$ & $2.4(1.2-5.0)$ & 100 & & & \\
\hline \multicolumn{6}{|l|}{ Obese } \\
\hline$N$ & 28 & 512 & & & \\
\hline$\%(95 \% \mathrm{Cl})$ & $3.8(2.2-6.5)$ & 100 & & & \\
\hline Physically active & & & & & \\
\hline Yes & & & & & \\
\hline$N$ & 13 & 138 & & & \\
\hline$\%(95 \% \mathrm{Cl})$ & $4.5(2.1-9.7)$ & 100 & $F(1,1 / 9)=3.30 / 8$ & 0.07 & $1.1-1.3$ \\
\hline No & & & & & \\
\hline$N$ & 74 & 2,106 & & & \\
\hline$\%(95 \% \mathrm{Cl})$ & $2.2(1.4-3.2)$ & 100 & & & \\
\hline Chest pain & & & & & \\
\hline Yes & & & & & \\
\hline$N$ & 23 & 73 & & & \\
\hline$\%(95 \% \mathrm{Cl})$ & $37.5(21.9-56.1)$ & 100 & $F(1,1 / 9)=145.2832$ & $<0.001$ & $1.2-1.3$ \\
\hline No & & & & & \\
\hline$N$ & 61 & 2,171 & & & \\
\hline$\%(95 \% \mathrm{Cl})$ & $1.7(1.1-2.6)$ & 100 & & & \\
\hline Hypertension & & & & & \\
\hline Yes & & & & & \\
\hline$N$ & 29 & 657 & & & \\
\hline$\%(95 \% \mathrm{Cl})$ & $2.2(1.1-4.2)$ & 100 & $F(1,179)=0.0296$ & 0.86 & $1.2-1.4$ \\
\hline No & & & & & \\
\hline$N$ & 55 & 1,587 & & & \\
\hline$\%(95 \% \mathrm{Cl})$ & $2.4(1.5-3.7)$ & 100 & & & \\
\hline Diabetes & & & & & \\
\hline Yes & & & & & \\
\hline$N$ & 22 & 498 & & & \\
\hline$\%(95 \% \mathrm{Cl})$ & $1.6(0.8-3.1)$ & 100 & $F(1,179)=1.3373$ & 0.25 & $0.9-1.4$ \\
\hline No & & & & & \\
\hline$N$ & 62 & 1,746 & & & \\
\hline$\%(95 \% \mathrm{Cl})$ & $2.5(1.6-3.7)$ & 100 & & & \\
\hline
\end{tabular}


Table 3 (continued)

\begin{tabular}{|c|c|c|c|c|c|}
\hline \multirow[t]{2}{*}{ Associated factor } & \multicolumn{2}{|c|}{ Depressive disorders } & \multirow{2}{*}{$\begin{array}{l}\mathrm{X}^{2} \text { with second-order } \\
\text { Rao-Scott correction }\end{array}$} & \multirow[t]{2}{*}{$p$ value } & \multirow[t]{2}{*}{ Deft } \\
\hline & $\begin{array}{l}\text { yes } \\
(n=84)\end{array}$ & $\begin{array}{l}\text { total } \\
(n=2,244)\end{array}$ & & & \\
\hline \multicolumn{6}{|l|}{ History of asthma } \\
\hline \multicolumn{6}{|l|}{ Yes } \\
\hline$N$ & 23 & 78 & \multirow{2}{*}{$F(1,179)=72.9687$} & \multirow{2}{*}{$<0.001$} & \multirow{2}{*}{$1.3-1.4$} \\
\hline$\%(95 \% \mathrm{Cl})$ & $28(14.4-47.3)$ & 100 & & & \\
\hline \multicolumn{6}{|l|}{ No } \\
\hline$N$ & 61 & 2,166 & & & \\
\hline$\%(95 \% \mathrm{Cl})$ & $1.7(1.1-2.7)$ & 100 & & & \\
\hline \multicolumn{6}{|l|}{ History of cancer } \\
\hline \multicolumn{6}{|l|}{ Yes } \\
\hline$N$ & 2 & 17 & \multirow{2}{*}{$F(1,179)=3.8528$} & \multirow{2}{*}{0.05} & \multirow{2}{*}{$0.6-1.4$} \\
\hline$\%(95 \% \mathrm{Cl})$ & $10.5(2.0-40.2)$ & 100 & & & \\
\hline \multicolumn{6}{|l|}{ No } \\
\hline$N$ & 82 & 2,227 & & & \\
\hline$\%(95 \% \mathrm{Cl})$ & $2.3(1.6-3.3)$ & 100 & & & \\
\hline \multicolumn{6}{|l|}{ History of stroke } \\
\hline \multicolumn{6}{|l|}{ Yes } \\
\hline$N$ & 4 & 14 & \multirow{2}{*}{$F(1,179)=49.2289$} & \multirow{2}{*}{$<0.001$} & \multirow{2}{*}{$0.4-1.4$} \\
\hline$\%(95 \% \mathrm{Cl})$ & 34.7 (13.7-64.0) & 100 & & & \\
\hline \multicolumn{6}{|l|}{ No } \\
\hline$N$ & 80 & 2,230 & & & \\
\hline$\%(95 \% \mathrm{Cl})$ & $2.3(1.6-3.3)$ & 100 & & & \\
\hline \multicolumn{6}{|l|}{ History of TB } \\
\hline \multicolumn{6}{|l|}{ Yes } \\
\hline$N$ & 19 & 92 & \multirow{2}{*}{$F(1,179)=45.7507$} & \multirow{2}{*}{$<0.001$} & \multirow{2}{*}{$1.2-1.7$} \\
\hline$\%(95 \% \mathrm{Cl})$ & $22.8(9.8-44.5)$ & 100 & & & \\
\hline \multicolumn{6}{|l|}{ No } \\
\hline$N$ & 65 & 2,152 & & & \\
\hline$\%(95 \% \mathrm{Cl})$ & $1.7(1.2-2.5)$ & 100 & & & \\
\hline
\end{tabular}

Deft, design factor; $\mathrm{Cl}$, confidence interval; $\mathrm{NCD}$, noncommunicable disease; $\mathrm{BMI}$, body mass index; $N$, number; $\mathrm{TB}$, tuberculosis.

Table 4. Predictors of depressive disorders among adult population aged $\geq 18$ years in Dubai 2019

\begin{tabular}{llllll}
\hline Depressive disorders $(n=2,224)$ & OR & & $95 \% \mathrm{Cl}$ & $p$ value & Comparison group \\
\hline Married & 2.7 & 1.2 & 6.3 & 0.022 & Not married \\
Employment & & & & & \\
$\quad$ Out of workforce & 0.3 & 0.1 & 1.1 & 0.078 & Unemployed \\
$\quad$ Employed & 0.2 & 0.1 & 0.7 & 0.008 & Unemployed \\
$\quad$ Smoking & 3.3 & 1.4 & 8.0 & 0.008 & Nonsmoking \\
$\quad$ Chest pain & 20.2 & 5.5 & 74.8 & 0 & No chest pain \\
$\quad$ History of TB & 12.6 & 2.1 & 76.8 & 0.006 & No history of TB \\
$\quad$ History of stroke & 22.5 & 6.8 & 74.2 & 0 & No history of stroke \\
\hline
\end{tabular}

F-adjusted test statistic $=F(5,175)=2.054 \times 10^{31} . p$ value $=0.000 . \mathrm{Cl}$, confidence interval; TB, tuberculosis; OR, odds ratio.

Depressive Disorders and Associated Factors among Adult Population of Dubai 
encountered TB. People with a history of stroke had 22.5 times higher odds of being depressed than those who had not had the condition.

\section{Discussion}

This is the first population level study on the prevalence of depressive disorders among the population of cosmopolitan Dubai. In this study, we reported Deft to enable the readers to better judge the efficiency of this complex-design study with its multistaging, stratification, and clustering. Deft is a quantitative toll expressing the relative size of variance from complex sample design divided by variance of the SRS. A value of 1 indicates that the standard error (SE) obtained for both designs (the complex and the SRS) is equal, meaning complex sampling is as efficient as the SRS with the same-sized sample. In our study, some Deft values were $>1$, the highest reached was 1.7 , indicating that that SE interval is 0.7 -folds greater than what would have been obtained with the SRS. Some Deft values were $<1$, with the lowest reaching 0.4 , indicating that our SE is about half that which would have been obtained from the SRS. Overall, our complex design study yielded a reasonable Deft [14].

This study revealed that the prevalence of depressive disorders was low in Dubai reaching up to 2.3\% (95\% CI: $1.6 \%-3.4 \%$ ). The prevalence included both (a) those who self-reported a diagnosis of depression and (b) those who were found to be screened positive for depressive disorders using the PHQ-9 tool. Globally, the 12-month prevalence of depressive disorders was approximately $6 \%$ [15]. Countries reporting more or less similar population prevalence included urban Spain 2000 with 1.8\% (95\% CI: 1.1\%-3.0\%) [15], China 2009 3.8\%, Japan 2008 2.2\% [7], and urban Finland 2000 4.7\% (95\% CI: 3.0\%-7.3\%) [16]. Countries with a higher prevalence range included Germany 2012 reporting $7.4 \%$ (95\% CI: 6.1\%-8.8\%) [17], the USA 2008 8.3\% [7], and urban Ireland 2000 8.9\% (95\% CI: 3.8\%-19.4\%) [13]. The highest prevalence was found in urban UK 2000 with 15\% (95\% CI: 8.8\%-24.4\%) [13] and Brazil 10.4\% [7].

The relatively low rate of depressive disorders in Dubai could be explained by the positive manifestation of determinants of mental well-being such as stability in socioeconomic and political factors in addition to access to health-care services. In the socioeconomic and political context, Dubai has a low unemployment rate. The citizens of Dubai enjoy government-funded social security programs and financial support for the disabled, elderly, and unemployed. Dubai is a politically stable emirate with good law enforcement and low crime rates.

Further, all citizens have access to free health and educational services. All Dubai inhabitants have universal health insurance granting access to emergency, outpatient, and inpatient health-care services. However, it should be noted that some health insurance programs provide restrictive access to mental health outpatient and inpatient care.

The study found that among all those with depressive disorders, $74 \%(n=62)$ did not report a previous diagnosis of depression and were only screened positive during the survey. Other population-based studies reported screened positive ranging widely from $30 \%$ in Japan and India to $60 \%$ in France, New Zealand, the USA, Brazil, and Ukraine [14]. The majority of individuals were suffering from undiagnosed depressive disorder, indicating problems accessing mental health services either due to stigma against mentally ill people or financial restrictions and cost of treatment. Mental health services are expensive, and not all health insurance programs provide cover for nonemergency services. Thus, individuals with limited mental health insurance programs - covering only emergency mental health conditions - do require paying out of pocket for outpatient care and inpatient services, counseling and medications. Effective strategies for improving accessibility for services needs further enhancement.

In terms of sociodemographic factors, several community epidemiological studies have found an association between depressive disorders and gender, age and marital status $[7,18]$. However, our study in Dubai found no association with gender, age, or educational background, but a positive correlation was found with marital status and employment. In Dubai, being unmarried - whether single, divorced, or widowed - had 2.7 times higher odds of having a depressive disorder than being married $(p<$ $0.05)$. The study did not set out to explain the antecedents of these associations between marriage and depressive disorders, which require further study. The study showed that being employed was a protective factor for depressive disorders; the likelihood of having depressive disorders was $80 \%$ lower among employed than unemployed who are looking for a job (OR $=0.2$ with $p<0.05)$.

In terms of NCD risk factors, there is literature evidence for a positive association between depression and smoking [19] and physical inactivity [20]. Our study in Dubai found a significant association with smoking but not with physical activity. Among the Dubai population, smokers had a 3.3 times higher chance of having depressive disorders than nonsmokers. 
Literature studies also report a correlation between depressive disorders and chronic conditions such as obesity, cardiovascular disease including stroke [21], diabetes, asthma, arthritis, cancer [19], unspecific chest pain regardless of significant cardiac disease [22], and history of TB [23]. In this study, we found that those who reported having chest pain had 20 times higher odds of being depressed than those who had not reported chest pain. Moreover, those who had a history of TB had 12.6 times higher odds of being depressed than those who had not encountered TB. People who self-reported a history of stroke had 22.5 times higher odds of being depressed than those who had not reported the same. However, the OR for self-reported chest pain, history of TB, and history of asthma had very wide $\mathrm{CI}$, and this significant result should be interpreted cautiously, requiring further studies. Also, our study could not find an association between obesity, hypertension, diabetes, or history of cancer and depressive disorders.

\section{Limitation of the Study}

Although the study found an association between marital status, employment status, smoking, having chest pain, stroke, or TB and depressive disorders, further studies are needed to study the antecedents to these associations, for example, whether being unemployed leads to the development of depressive disorders or depressive disorders leads to being unemployed? Future research must include factors that were not studied in this work such as substance abuse and additional health conditions.

\section{Conclusion}

The prevalence of depressive disorders in Dubai is low compared to internationally published figures; however, as with other parts of the world, majority of individuals remain undiagnosed. There were significant associations between depression and being unmarried, smoking, and having health conditions, such as chest pain, history of stroke, and history of TB. The direction of association needs further studies. Moreover, the study did not find a significant association between depression and gender, age-group, educational background, BMI, hypertension, diabetes, or history of cancer.

\section{Recommendations}

The current survey is informative for policy makers when planning for public health interventions and when designing public health promotion and prevention pro- grams. Mental health promotion programs need to target adults with a profile of being unmarried, smoking, and exhibiting health conditions like chest pain, history of stroke, and TB. Further population level research is needed to study other relations not included in this paper.

\section{Acknowledgment}

We appreciate the contribution of Dr. Nehad Mahdy, Dr. Badreyya AlHarmi, Dr. Waleed Al Faisal, Dr. Nadia Dabbagh, and Dr. Samia Alkhoori, the Dubai Household Survey Working Team, all staff of data analysis, research, and studies department, especially Dr. Hamid Hussein and Dr. Heba Mamdouh.

\section{Statement of Ethics}

As per Dubai Health Authority protocols, the study was defined as nonhuman subject research. Ethical approval was not required for this study based on an exemption letter from the Dubai Scientific Research Ethics Committee (number "DSRECGL03-2021," date 23 May 2021). Ethical standards were adhered to throughout this study. Consent to participate was obtained from all the household heads who voluntarily accepted to participate.

\section{Conflict of Interest Statement}

The authors have no conflicts of interest to declare.

\section{Funding Sources}

None.

\section{Author Contributions}

Dr. M.A. contributed to tools, data management and analysis, and writing manuscript. Dr. S.F. contributed to tools, data analysis, and writing manuscript. Dr. A.A. contributed to writing manuscript. Ms. F.R. contributed to data analysis. Ms. H.J. contributed to data analysis. Dr. K.A. contributed to data analysis and writing manuscript.

\section{Data Availability Statement}

The data that support the findings of this study are not publicly available due to organization's administrative policy and procedures. However, the data are available from the corresponding author upon reasonable request.
Depressive Disorders and Associated Factors among Adult Population of Dubai
Dubai Med J 2021;4:291-300

DOI: $10.1159 / 000518811$ 


\section{References}

1 The world health report 2001: mental disorders affect one in four people. Geneva: World Health Organization; 2011 [cited 2020 Jan]. Available from: https://www.who.int/ whr/2001/media_centre/press_release/en/.

2 Mental Disorders. Geneva: World Health Organization; 2019 [cited 2020 Jan]. Available from: https://www.who.int/news-room/factsheets/detail/mental-disorders.

3 Ferrari AJ, Charlson FJ, Norman RE, Patten SB, Freedman G, Christopher JL, et al. Burden of depressive disorders by country, sex, age, and year: findings from the Global Burden of Disease Study 2010. PLoS Med. 2013 Nov; 10(11):e1001547.

4 Depression and other common mental disorders: global health estimates. Geneva: World Health Organization; 2017. Licence: CC BYNC-SA 3.0 IGO.

5 Andrade L, Caraveo-Anduaga JJ, Berglund P, Bijl RV, De Graaf R, Vollebergh W, et al. The epidemiology of major depressive episodes: results from the international consortium of psychiatric epidemiology (ICPE) surveys. Int J Methods Psychiatr Res. 2003;12(1):3-21.

6 Moussavi S, Chatterji S, Verdes E, Tandon A, Patel V, Ustun B. Depression, chronic diseases, and decrements in health: results from the world health surveys. Lancet. 2007;370(9590): 851-8.

7 Kessler RC, Bromet EJ. The epidemiology of depression across cultures. Annu Rev Public Health. 2013;34:119-38.

8 Arvind BA, Gururaj G, Loganathan S, Amudhan S, Varghese M, Benegal V, et al. Prevalence and socioeconomic impact of depressive disorders in India: multisite populationbased cross-sectional study. BMJ Open. 2019; 9(6): 027250
9 Ghubash R, Hamdi E, Bebbington P. The Dubai community psychiatric survey: I. Prevalence and socio-demographic correlates. Soc Psychiatry Psychiatr Epidemiol. 1992;27(2): 53-61.

10 Benefits of depression interventions. Atlanta: CDC; 2016 [cited 2020 Jan]. Available from: https: //www.cdc.gov/workplacehealthpromotion/health-strategies/depression/interventions/benefits.html.

11 StataCorp. Stata survey data reference release 13. TX, USA: StataCorp.; 2013. (ISBN-13: 978-1-59718-125-9).

12 Archer KJ, Stanley L. Goodness-of-fit test for a logistic regression model fitted using survey sample data. Stata J. 2006;6(1):97-105.

13 Population by Gender and Age Groups Emirate of Dubai (2018-2017, 2005). UAE: Dubai Statistics Center; 2018. [cited Jan 2020]. Available from: https://www.dsc.gov.ae/Report/DSC_SYB_2018_01\%20_\%2005.pdf.

14 Heeringa SG, West BT, Berglund PA. Applied Survey Data Analysis. Michigan, USA: CRC Press; 2017.

15 Bromet E, Andrade LH, Hwang I, Sampson NA, Alonso J, De Girolamo G, et al. Crossnational epidemiology of DSM-IV major depressive episode. BMC Med. 2011;9(1):90

16 Ayuso-Mateos J, Vázquez-Barquero JL, Dowrick $\mathrm{C}$, Lehtinen V, Dalgard OS, Casey $\mathrm{P}$, et al. Depressive disorders in Europe: prevalence figures from the ODIN Study. Br J Psychiatry. 2001;179(4):308-16.
17 Bretschneider J, Janitza S, Jacobi F, Thom J, Hapke U, Kurth T, et al. Time trends in depression prevalence and health-related correlates: results from population-based surveys in Germany 1997-1999 vs. 2009-2012. BMC Psychiatry. 2018;18:364.

18 LaPierre TA. Marital status and depressive symptoms over time: age and gender variations. Fam Relat. 2009;58(4):404-16.

19 Weinberger AH, Kashan RS, Shpigel DM, Esan H, Taha F, Lee CJ, et al. Depression and cigarette smoking behavior: a critical review of Population-Based Studies. Am J Drug Alcohol Abuse. 2017;43(4):416-31.

20 Centers for Disease Control and Prevention (CDC). Current depression among adults: United States, 2006 and 2008. MMWR Morb Mortal Wkly Rep. 2010;59(38):1229-35.

21 Robinson RG, Jorge RE. Post-stroke depression: a review. Am J Psychiatry. 2016;173(3): 221-31.

22 Kim Y, Soffler M, Paradise S, Jelani QU, Dziura J, Sinha R, et al. Depression is associated with recurrent chest pain with or without coronary artery disease: a Prospective Cohort Study in the emergency department. Am Heart J. 2017;191:47-54.

23 Koyanagi A, Vancampfort D, Carvalho AF, DeVylder JE, Haro JM, Pizzol D, et al. Depression comorbid with tuberculosis and its impact on health status: cross-sectional analysis of community-based data from 48 low- and middle-income countries. BMC Med. 2017; 15(1):209. 